\title{
Imaginarios urbano-rurales en el barrio EI Salado de lbagué, Colombia
}

\author{
Imaginários urbanos-rurais no bairro El Salado do Ibagué, Colômbia \\ Urban-rural imaginaries at the Salado neighborhood in Ibagué, Colombia
}

Angela María Lopera Molano [a] (D), Carlos Mauricio Santana Sáenz [a] (DD)

[a] Universidad de Ibagué (SIGLA), Ibagué, Colombia

Cómo citar: Lopera Molano, A. M., \& Santana Sáenz, C. M. (2021). Imaginarios urbano-rurales en el barrio El Salado de Ibagué, Colombia. urbe. Revista Brasileira de Gestão Urbana, v.13, e20200104. https://doi.org/10.1590/2175-

3369.013.e20200104

\section{Resumen}

Este artículo presenta el estudio realizado al barrio Especial El Salado de la ciudad de Ibagué en Colombia, en el que se identificaron cómo las formas de significación de los habitantes dinamizan el territorio. El territorio es entendido como un hecho vivencial dinámico y cargado de simbologías que provienen de los imaginarios de los ciudadanos. La metodología de la investigación se realizó desde un enfoque cualitativo a partir de un cuestionarioencuesta y entrevistas semiestructuradas, que se correlacionaron a partir de la identificación de patrones y campos semánticos. Se logró encontrar que lo que caracteriza al territorio en el barrio es que tiene una dinámica urbano-rural en la que se problematizan los cambios generados por el crecimiento urbanístico del barrio y la importancia que tiene lo histórico y patrimonial en la configuración de un territorio turístico con características rurales.

Palabras clave: Territorio. Imaginarios urbanos. apropiación del espacio. Ciudad. Barrio.

\section{Resumo}

Este artigo apresenta o estudo desenvolvido no bairro Especial El Salado da cidade de Ibagué, na Colômbia, no qual identificou-se como as formas de significado dos habitantes energizam o território. 0 território é entendido como um fato experimental dinâmico e carregado de simbologias que provêm do imaginário dos cidadãos. A metodologia da pesquisa foi realizada a partir de uma abordagem qualitativa, baseada em um questionáriopesquisa e entrevistas semiestruturadas, que foram correlacionadas a partir da identificação de padrões e campos semânticos. Foi possível constatar que o que caracteriza o território no bairro é que ele possui uma dinâmica urbano-rural na qual são problematizadas as mudanças geradas pelo crescimento urbano do bairro e a importância do histórico e do patrimônio na configuração de um território turístico. com características rurais.

Palavras-chave: Território. Imaginário urbano. apropriação do espaço. Cidade. Bairro. 


\section{Abstract}

This article presents the study carried out in El Salado Special neighborhood of the city of Ibague in Colombia, which identified how the forms of meaning of the inhabitants changes the territory. The territory is understood as a dynamic experiential fact and loaded with symbologies that come from the imaginary of the citizens. The research methodology was carried out from a qualitative approach based on a questionnaire-survey and semi-structured interviews, which were correlated from the identification of patterns and semantic fields. It was possible to find that what characterizes the territory in the neighborhood is that it has an urban-rural dynamic in which the changes generated by the urban growth of the neighborhood and the importance of the historical and heritage in the configuration of a tourist territory are problematized. with rural characteristics.

Keywords: Territory. Urban imaginaries. Appropriation of space. City. Neighborhood.

\section{Introducción}

Recientes estudios sobre el territorio han buscado la forma de articular las visiones economicistas y geográficas sobre este concepto (Giménez, 2005; Pecqueur, 2009; Martínez-Valle, 2012). Sin embargo, se siguen imponiendo en las ciudades procesos institucionales para definir el territorio, lejanos de los procesos sociales de sus habitantes (Giménez, 2005; Mazurek, 2005). Estos procesos institucionales se refieren a la planificación del territorio, en los que la tarea de los gobiernos es definir los límites que separan uno y otro espacio para la distribución de los recursos (Mazurek, 2005), por tanto, "hoy resulta notorio que ha quedado relegado el componente socio-cultural de los procesos de conformación del espacio urbano durante largos años" (Lindón et al., 2006, p.15).

La noción de territorio de la que partimos tiene que ver con los procesos de apropiación social y de diferenciación de quienes habitan y usan el espacio (Mazurek, 2005), en este caso concreto, de un barrio de la ciudad de Ibagué en Colombia. Lo anterior implica pensar este barrio más allá de su configuración espacial y material, para comprender las dinámicas socio-culturales en las que está inserto, "como lugar del acontecimiento cultural y escenario de un efecto imaginario, los símbolos que sobre ella [este] construyen sus propios habitantes" (Jaramillo Paredes, 2013, p. 27).

Por consiguiente, paralelo a los procesos de ordenamiento territorial, los ciudadanos viven la ciudad en su cotidianidad y generan representaciones de esta. Estas representaciones surgen a partir de imaginarios colectivos que se dan en la relación entre la ciudad como hecho físico y las formas de habitarla (Silva, 2004, 2006). Para poder realizar un acercamiento al barrio proponemos que el enfoque sea desde los imaginarios urbanos, es decir, desde la dimensión subjetiva de los ciudadanos, de las personas que hacen uso del espacio, se apropian y a la vez lo construyen socialmente. Lo que deviene de este acercamiento es "la comprensión simbólica individual y colectiva de los territorios urbanos" (Hiernaux, 2006, p. 29). Esto podrá evidenciar cómo desde el deseo se transforma su territorio y adquiere otras posibilidades para ser habitado (Silva, 2011, 2013, 2015). Aspecto central para poder comprender la condición dinámica y procesual del concepto de territorio (Ciccolella, 2011); que se modifica en la interacción entre los diferentes actores en la vida cotidiana.

Para el desarrollo de este trabajo se tomó como base la investigación Ibagué imaginada (Silva, 2004, 2006; Lopera et al., 2019) en la que se participó como investigadores. A partir de ese aporte se identificaron ciertas dinámicas del barrio El Salado de la ciudad de Ibagué ancladas a una noción del territorio como un espacio de significación defendido culturalmente por sus habitantes. Los imaginarios urbanos que se han generado sobre este barrio entran en tensión con una ciudad, categorizada en Colombia como una ciudad intermedia, que quiere ser moderna, y un barrio que está insertado en lo urbano, pero quiere mantener las costumbres rurales que lo originaron. Además, hay dos miradas contrapuestas que lo señalan como un territorio históricamente valioso, pero que es visto como una otredad (Silva, 2004), frente al resto de los barrios que desconocen sus orígenes (Lopera et al., 2019). De aquí se desprenden las dos preguntas de investigación que se propusieron: ¿Cuáles son los imaginarios urbano-rurales que surgen de las percepciones de los habitantes de El Salado sobre su propio barrio? y ¿cuáles son las formas de significación que adquiere el territorio para los habitantes del barrio El Salado de la ciudad de Ibagué? 


\section{Estado de la cuestión}

Las investigaciones que abordan los imaginarios de los procesos urbanos en las ciudades contemporáneas se enfocan en las tendencias de fragmentación del espacio materializado, la suburbanización, el regreso a los centros históricos, la globalización y la apropiación simbólica del espacio (Lindón et al., 2006; Ortiz Guitart, 2006; Lindón, 2006; Guerrero Valdebenito, 2006; Martel \& Baires, 2006). No obstante, priman las investigaciones relacionadas con ciudades capitales (espacios concretos o barrios), mientras que los estudios urbanos sobre ciudades pequeñas o intermedias apenas han comenzado a representar un interés por parte de investigadores de las ciencias sociales (Silva, 2019; Antequera, 2007). Esto se debe a que brindan un panorama más amplio sobre los cambios en la vida urbana de un país. La mayoría de estas investigaciones son estudios de caso, que permiten evidenciar realidades concretas $\sin$ llegar a generalizaciones. No obstante, el andamiaje teórico y metodológico de los imaginarios que comparten permite hacer comparaciones más amplias sobre las formas en las que habitamos nuestras ciudades (Aliaga et al., 2018). Por consiguiente, estudiar un barrio de una ciudad intermedia permite evidenciar los cambios en el territorio desde una perspectiva más amplia y descentralizada.

Los empalmes y las superposiciones entre lo urbano y lo rural generan una simbiosis de expresiones territoriales (Ávila Sánchez, 2005) o figuras híbridas entre lo rural y lo urbano (Méndez, 2005). Su comprensión es necesaria para estudiar la sociedad contemporánea y las formas en las que se relacionan los actores allí implicados. Por ejemplo, la construcción de identidades, los procesos de representación o imaginarios; así como los procesos de creación de sentidos y la producción de significado social (Winocur, 2009).

Esta lectura no está exenta de los cambios que genera la globalización o los efectos que tiene el capitalismo global (Ciccolella, 2011) frente a procesos de apropiación del territorio anclados a dinámicas identitarias y culturales. Es importante tener en cuenta que en la relación entre lo local y lo global se hace necesario comprender que los modos de apropiación del espacio, que van a configurar el territorio, son expresiones de una o de diversas experiencias culturales y, por tanto, los grandes proyectos urbanos, la recualificación de espacios degradados y la mercantilización de las ciudades (Vera, 2018), producto del capitalismo global, interactúan con procesos, a pequeña escala, ligados a imaginarios colectivos anclados al territorio.

Por otro lado, la tendencia a trabajar las relaciones entre el centro y periferia de las ciudades se enfoca en la comprensión de escenarios o prácticas de segregación y conflicto (Santillán, 2019; García Ayala, 2016; Guerrero Valdebenito, 2006; Lindón, 2006) en el que el sentimiento del miedo prima como imaginario colectivo (Silva, 2013, 2015). La relación con la otredad se desprende de lo anterior, dado que la exclusión de sectores, grupos o barrios genera la categoría de marginalidad (Arizaga, 2000) en la que el otro es representado como diferente a mí (Silva, 2006). La segregación se concreta en el espacio urbano, a partir de las representaciones sociales que se generan hacia el otro y las particularidades de los procesos históricos de cada sector o grupo (Pérez-Rincón et al., 2012; Palacios-Gámaz, 2010).

Para el caso de los imaginarios urbanos del proyecto de las Ciudades Imaginadas (Silva, 2004, 2006) la otredad se concreta en relación con el otro-ciudad, pero no desde el barrio como otredad de la ciudad. En la investigación se abordó al barrio El Salado desde la relación centro-periferia, sin embargo, en este caso se enfatizó en la relación de otredad, dado que se asume en el imaginario de los habitantes como rural.

Como lo afirma Pecqueur (2009), el territorio es vivido y percibido, por consiguiente, no puede ser medido de la misma manera, depende de la interacción de los actores, "de las estrategias de aquellos y de su grado de organización" (Martínez-Valle, 2012, p. 13-14). En tal sentido, Mazurek (2005, p. 3) afirma que "lo que transforma un espacio en territorio es el proceso de apropiación y de diferenciación".

En esa medida, ya no hablamos solamente de territorio, sino de la construcción social del territorio que implica una lectura más amplia que la que imponen las relaciones productivas de nuestras sociedades. "Son precisamente los actores sociales quienes construyen un territorio, para lo cual deben cooperar a fin de implementar proyectos colectivos y apropiarse de los recursos [...]" (Martínez-Valle, 2012, p. 13).

Giménez (2005) añade la importancia de tener en cuenta la percepción vivencial del territorio, que tiene que ver con los imaginarios colectivos que tienen en su base sentimientos compartidos sobre el territorio y que modifican las formas de apropiación del espacio. Recordemos que "las representaciones sociales funcionan como materialización o anclaje de los imaginarios por poseer menor nivel de abstracción" (Vera, 2018, p. 51), por lo tanto, pueden identificarse en situaciones u objetos de la ciudad.

La ciudad es un constructo imaginario, "es sobre todo un campo de significaciones. Son esas significaciones las que proveen la materia prima de la que está hecha la experiencia urbana" (Delgado, 2007, 
p.181). En consecuencia, entendemos que los imaginaros urbanos estudian las culturas ciudadanas y que sus investigaciones avanzan hacia la construcción de una teoría del sentir ciudadano como expresión de deseos hechos colectivos por su coincidencia en la búsqueda del mismo objeto. En rigor, son los imaginarios urbanos los que habitan a sus ciudadanos (Silva, 2007).

\section{El caso de estudio del barrio Especial El Salado}

La ciudad de Ibagué está dividida en 13 comunas, el barrio Especial El Salado pertenece a la comuna 7, ubicada en el nororiente de la ciudad. En el Plan Estratégico de Desarrollo de esta comuna, presentado en el año 2012, se afirma que el barrio El Salado primero fue una vereda, luego un corregimiento y, finalmente, el 11 de septiembre de 1964, un barrio de la ciudad de Ibagué. El barrio fue denominado Especial por un Acuerdo Municipal que le brindó incentivos tributarios para su desarrollo. En 1988, a través del Acuerdo municipal No.74, el barrio es declarado "Patrimonio turístico de la ciudad musical de Colombia"1 y en el 2009, por medio del Acuerdo Municipal No. 009, se institucionalizó como Pueblito Tolimense ${ }^{2}$ para preservar su legado histórico y arquitectónico.

Según la información obtenida en el Centro de Información Municipal para la Planeación Participativa (CIMPP), actualmente el barrio El Salado cuenta con un parque central catalogado como el único espacio público, una iglesia católica en el parque, una plaza de mercado antigua y una plaza de mercado nueva, diferentes establecimientos comerciales y residencias. A su alrededor se encuentran urbanizaciones y edificios de más reciente construcción, como se evidencia en la figura 1 del mapa oficial del barrio y en la vista área del parque central del barrio de la figura 2 .

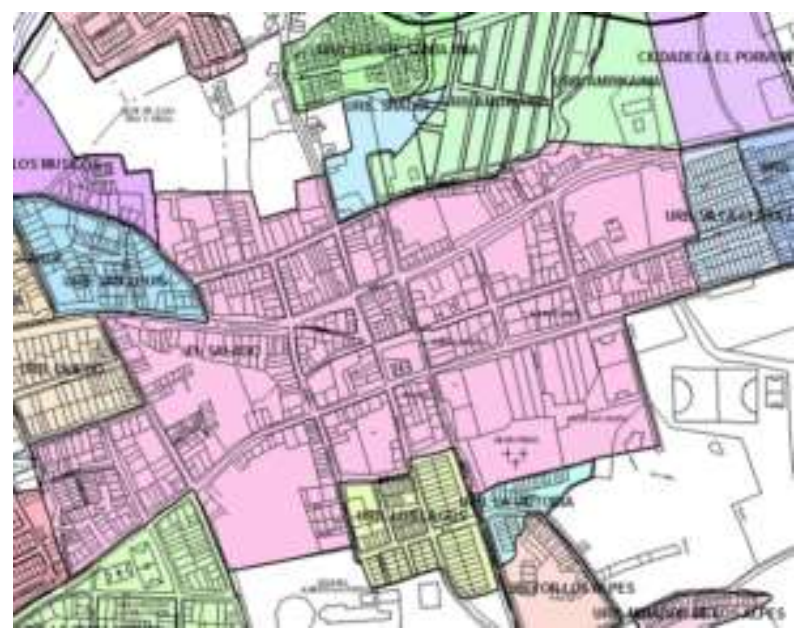

Figura 1 - Mapa del barrio El Salado (rosado a la izquierda). Fuente: Centro de Información Municipal (2019).

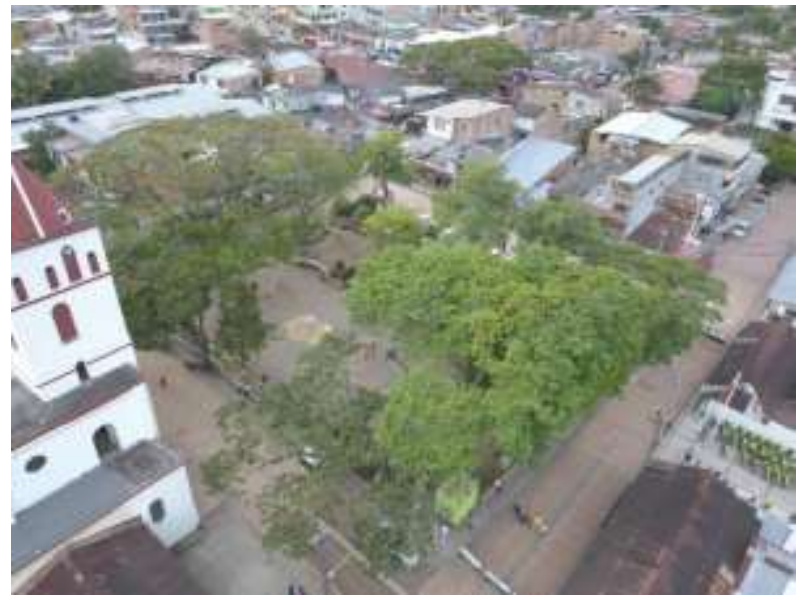

Figura 2 - Parque central del barrio (a la derecha). Fuente: Investigación Ibagué imaginada (2019).

\footnotetext{
${ }^{1}$ La ciudad musical de Colombia es Ibagué.

${ }^{2}$ Colombia, en su división político-administrativa tiene departamentos y capitales de departamentos. El Tolima es el departamento al que pertenece la ciudad de Ibagué, que es su capital.
} 
De acuerdo con el Anuario Estadístico Municipal 2016-2017, la Comuna 7 tiene una extensión de 5,2527 $\mathrm{km}^{2}$, es decir, es la segunda comuna más grande de la ciudad de Ibagué. Aunque en la actualidad El Salado es solo uno de los 79 barrios que conforman la comuna, cuando era una vereda y no hacía parte de la ciudad de Ibagué, su extensión era la de la comuna completa, como se muestra en la figura 3.

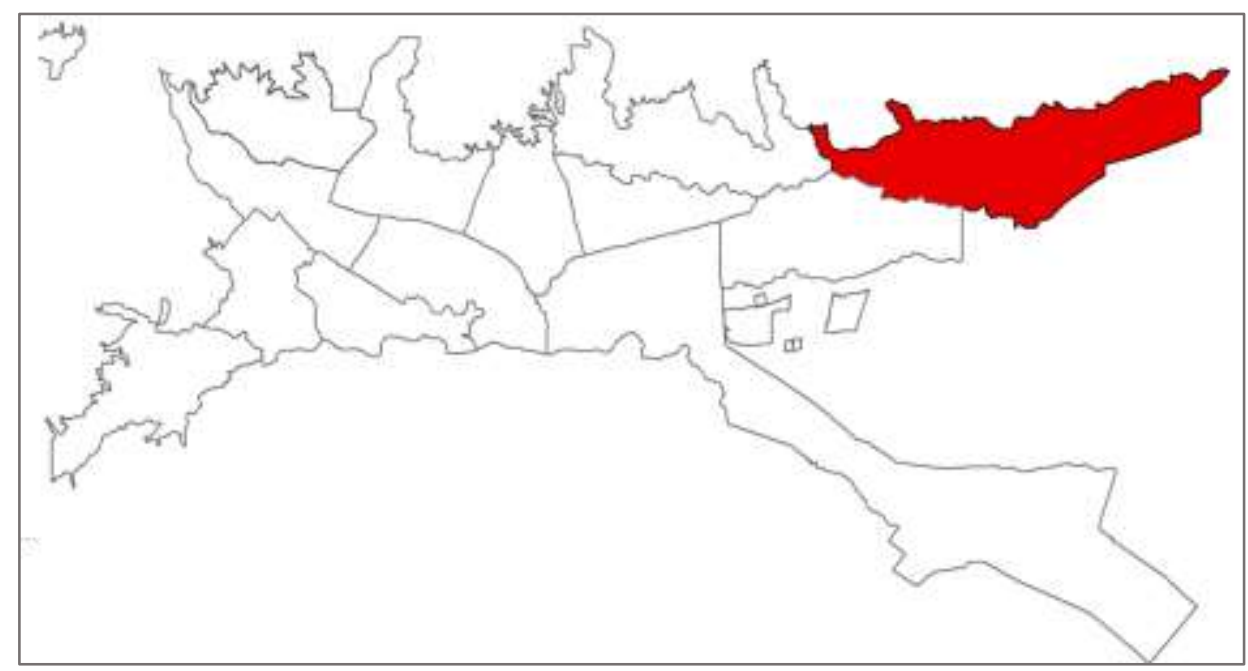

Figura 3 - Mapa de lbagué, en rojo la comuna 7. Fuente: Centro de Información Municipal (2019).

El barrio Especial El Salado es conocido como Pueblito Tolimense porque en este se mantienen diferentes costumbres tradicionales que le otorgan características rurales, a pesar de encontrarse en un medio urbano. El barrio se convirtió en un referente turístico gracias a los balnearios de la zona, las fincas agroturísticas y los recientes centros recreacionales.

\section{Método}

La investigación tiene un enfoque mixto que se sustenta en la necesidad de obtener información clave sobre las formas de significación del territorio y cómo estas inciden en las prácticas cotidianas de los habitantes. El desarrollo de esta investigación contó con tres fases:

La primera fase, que utilizó la encuesta como instrumento, corresponde al desarrollo metodológico realizado para la investigación Ibagué imaginada que tenía como objetivo general analizar los imaginarios urbanos creados por los ciudadanos de Ibagué. De esta investigación se tomaron datos estadísticos relevantes como base para identificar las percepciones imaginadas del barrio El Salado. Las respuestas fueron de 336 habitantes de toda la ciudad de Ibagué, pero para esta investigación se tomaron solo las alusiones concretas que referían al barrio El Salado.

La segunda fase consistió en un ejercicio cualitativo de observación del barrio y las actividades que se desarrollan en este, a partir de diarios de campo. Las visitas se realizaron de enero a junio de 2019. Todo este proceso fue documentado en fichas de observación y la categorización de las respuestas de las personas a diferentes preguntas relacionadas con el cuestionario de las ciudades imaginadas, a partir de la tríada: ciudad, ciudadanos y otredades.

En la tercera fase se trabajó a partir de entrevistas semiestructuras a profundidad con habitantes o trabajadores del barrio, con un muestro no probabilístico por conveniencia. Las preguntas se organizaron en tres bloques temáticos que permiten dar cuenta de la construcción social del territorio, en los que se indagó por las 1) rutinas cotidianas del uso del espacio público, los entornos habitacionales, que se convierten en extensiones de los hogares (García Ayala, 2016). 2) la historia, la tradición y el patrimonio. El patrimonio tiene que ver con el valor histórico de un lugar (Rodríguez Becerril, 2016). El pasado está en relación con el futuro, ya que permite que los ciudadanos evidencien los cambios históricos, identifiquen necesidades actuales y puedan proyectar un futuro para sus barrios, lo cual lleva a una redefinición de los escenarios de la vida pública (Petzol-Rodríguez, 2016).

Y 3) la apropiación simbólica, entendida como el uso provisional de un espacio, lo que genera variaciones en función de dicho uso (Monnet, 2015; Salvatierra, 2016). También, identificar la capacidad organizativa 
de una comunidad es una forma de apropiación y depende de la calidad del espacio público, ya que este permite su desarrollo y reproducción (Portal, 2016). Se realizaron 23 entrevistas porque había logrado alcanzar el punto de saturación en las respuestas. Finalmente se realizó un proceso de triangulación metodológica de los datos obtenidos en las tres fases de investigación, con el fin de ampliar la comprensión del fenómeno y validar la información obtenida (Hussein, 2009).

\section{Resultados}

De los resultados de la primera fase se obtuvieron datos sobre las percepciones imaginadas que surgieron de las 336 encuestas a ciudadanos de Ibagué, sobre el barrio El Salado. Los resultados de estos datos tienen un porcentaje bajo, debido a que solo dos preguntas indagaban directamente sobre el barrio, las demás alusiones se hicieron de manera espontánea por parte de los encuestados como respuesta a otras preguntas.

Los datos son los siguientes: 18 personas consideran que El Salado es un barrio que identifica a la ciudad de Ibagué (5.36\%); 3 personas destacan alguna parte del barrio como importante para representar la arquitectura de Ibagué $(0.8 \%)$; mientras que 37 personas se refirieron al barrio en preguntas sobre los sitios de diversión de Ibagué, aquellos que representan recreación, paseo en pareja o alegría (11\%); 28 personas se refirieron al barrio, por encima de otros lugares de la ciudad de Ibagué, para expresar que en este lugar está el olor más desagradable, es peligroso, sucio o triste (8.3\%). La percepción de lugares como El Salado se da cuando se pregunta por los sitios de diversión de la ciudad de Ibagué. En la figura 4 se muestran los resultados para toda la ciudad de Ibagué:

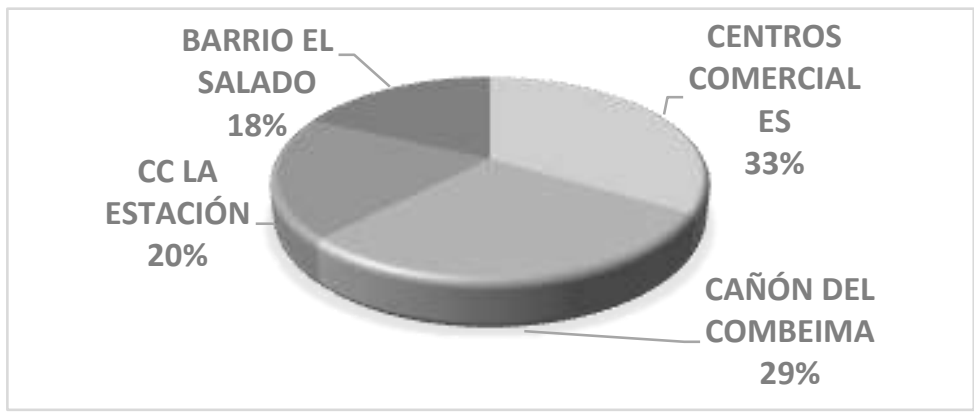

Figura 4 - Sitios de diversión de Ibagué. Fuente: investigación Ibagué imaginada (2019).

En la figura 5 se muestra la respuesta a la pregunta por el gusto que hay hacia el parque del barrio El Salado, donde 1 es nada y 5 mucho. Esta respuesta la dieron los 336 ciudadanos encuestados.

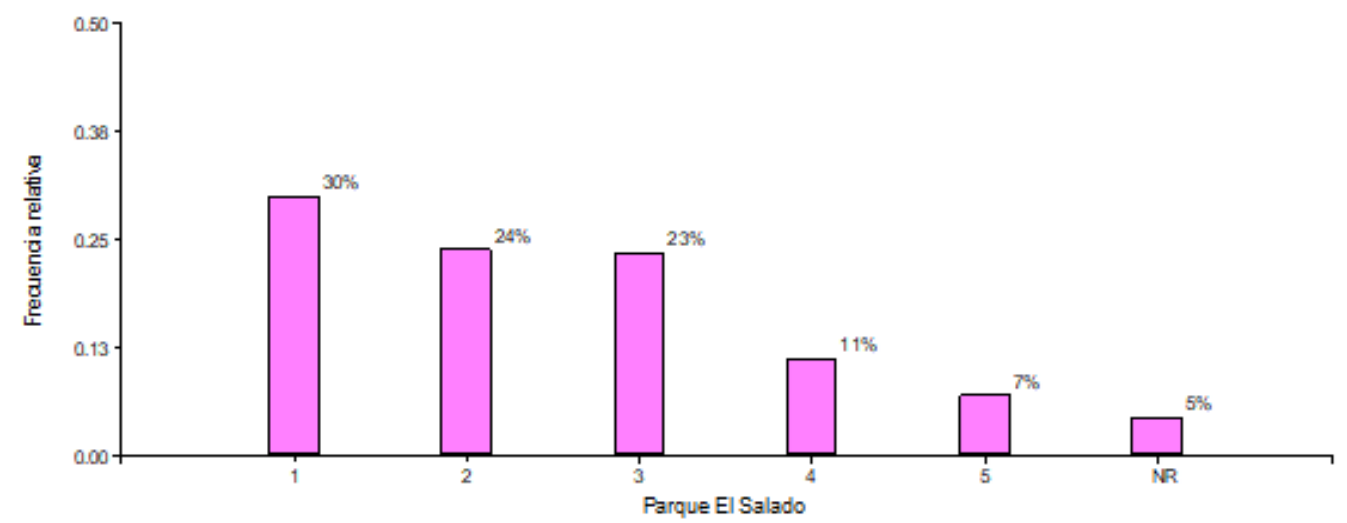

Figura 5 - Calificación del parque El Salado. Fuente: investigación Ibagué imaginada, (2019).

Como vemos, aparece más inclinado el gusto hacia lo negativo, es importante anotar que los lugares de diversión (centros recreacionales y fincas agroturísticas no se encuentran dentro del barrio, sino que están a los alrededores, de allí la contradicción entre las percepciones positivas y negativas sobre el mismo barrio). 
A continuación, en la figura 6 presentamos las respuestas de los 336 habitantes a la pregunta por la palabra o imagen que identifica al barrio El Salado:

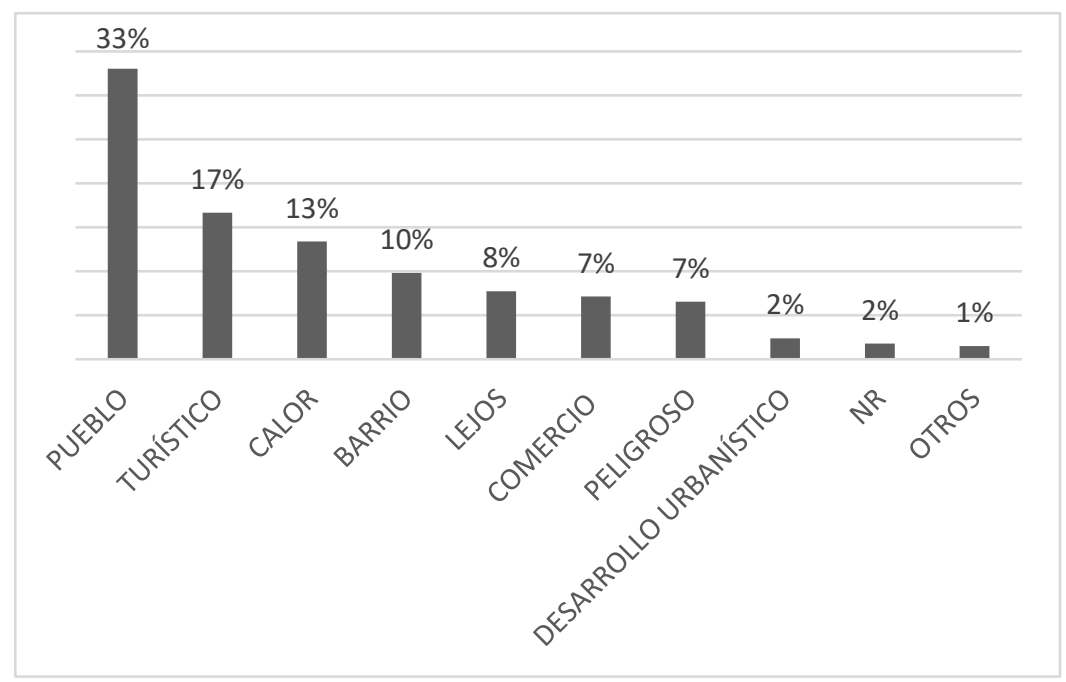

Figura 6 - Imagen o palabra que identifica al barrio El Salado. Fuente: Investigación Ibagué imaginada, 2019.

Los anteriores resultados muestran aspectos que ya se han señalado: la idea de periferia (lejano), peligro y lo turístico. Pero en primer lugar aparece un aspecto central en la percepción de los ciudadanos encuestados, más que un barrio, El Salado es considerado un pueblo. Este rasgo específico, que invita a ser interpretado, nos conduce a afirmar que el barrio aparece como una otredad.

Los resultados de la fase 2 , observación y diario de campo, se organizaron y codificaron en la matriz en la que se escribieron las fechas de la observación, los horarios y días de la semana, con las respectivas rutinas de los habitantes. A esta información se le agregó la codificación de la matriz de respuestas de la entrevista semiestructurada. De allí surgieron los siguientes resultados: 1) los límites y la extensión imaginada del barrio, 2) las historias sobre la historia del barrio Especial El Salado y 3) entre barrio, pueblo y pueblito tolimense.

\section{Los límites y la extensión imaginada del barrio}

Al no existir una historia oficial del barrio, aparecen versiones que se han apropiado de los relatos orales de sus padres y abuelos. Entre estas evocaciones a la historia señalan unos límites geográficos del barrio que son compartidos por los habitantes de manera tácita, es decir, sin cuestionamientos y por encima de las divisiones político-administrativas de la ciudad de Ibagué. Nos referimos al carácter imaginado que tienen los habitantes de su mismo barrio en términos de extensión, límites y población.

El barrio se caracteriza por las fincas, los caballos, la pesca, senderismo, masajes. Han llamado Salado a toda la Comuna 7 , también donde está el corregimiento 13, pero dicen que eso es Salado: la plaza, el comercio, la montaña, todo lo que involucra el tema turístico (Habitante de 60 años, 13 años en el barrio; Entrevista I, 2019).

En las percepciones de los habitantes sobre los lugares representativos del barrio y los usos que le dan a estos espacios, las delimitaciones se rompen y El Salado crece en extensión. Por ejemplo, tanto los ciudadanos que respondieron la encuesta de Ibagué imaginada y los habitantes del barrio que entrevistamos aseguran que los espacios más representativos del barrio son las fincas agroturísticas, los centros recreacionales y los ríos que rodean este territorio; además de otras alusiones a espacios deportivos o parques que se encuentran fuera de los límites del barrio El Salado y le pertenecen a otras urbanizaciones o zonas rurales.

Las personas que vienen al barrio vienen al turismo a los alrededores, a bañarse, a estarse en las fincas a pasarla rico el día domingo. El Salado es un lugar turístico por el tema de los balnearios. (Habitante de 34 años, toda la vida en el barrio; Entrevista VI, 2019). 
Como vimos en la delimitación del mapa oficial, esto no es cierto, pero tampoco es del todo falso. Cuando El Salado era un corregimiento de carácter netamente rural, todas estas fincas, piscinas naturales y ríos hacían parte de su extensión y quedaron en la mente de los ciudadanos. Lo anterior significa que los ciudadanos hemos elaborado un croquis afectivo de El Salado en el que se incluyen todos estos lugares (el parque central, la plaza de mercado, las fincas agroturísticas) y los nuevos centros de recreación, por encima del mapa oficial del barrio.

Los croquis son percepciones territoriales colectivas, estos tienen límites evocativos y metafóricos que manifiestan la subjetividad social. El territorio se denomina y recorre, es un espacio vivido, marcado y reconocido (Silva, 2004). Por lo tanto, la ciudad deja de ser un mapa estático y se convierte en múltiples croquis heterogéneos porque los imaginarios que habitan la ciudad se manifiestan allí y están presentes en la interacción social (García-Canclini, 2010). En este croquis del barrio se evidencian sus componentes urbano-rurales.

El imaginario sobre los límites y la extensión de El Salado se remite a su pasado como corregimiento, antes de convertirse en un barrio de Ibagué. No solo es una forma de evocación del barrio, sino de apropiación del espacio. Su anterior carácter rural se ha transformado en un imaginario de vida urbanorural que des-limita los límites impuestos y crea un croquis afectivo.

\section{Las historias sobre la historia del barrio Especial El Salado}

Las versiones de la historia del barrio afectan la manera en la que se vive el territorio, recordemos que el espacio público es un espacio histórico, es decir, un espacio con historia (Carrión, 2016). El origen del nombre del barrio representa un aspecto significativo para los habitantes, pero que se pierde en los más jóvenes que tienen un total desconocimiento de las raíces del barrio y el paso de la historia por los lugares que recorren diariamente. Aquí algunas versiones de los habitantes de mayor edad:

Había una finca que se llamaba el salado, con piedras salobres (porque esto antes fue un mar) y el ganado venía a lamer esas piedras, por eso se llama El Salado (Habitante de 77 años, 40 años en el barrio; Entrevista XXI, 2019).

Se llama El Salado porque bajaban los indios y se intercambiaba sal por ganado. (Habitante de 82 años, toda la vida en el barrio; Entrevista XIV, 2019).

Actualmente, el Acuerdo 009 del 11 de mayo de 2009, institucionalizó al barrio como Pueblito Tolimense, con el fin de promover el turismo, el comercio y la cultura. Además, garantizaría la pervivencia de la identidad cultural arquitectónica e histórica del barrio. Lo que encontramos en la investigación es que este Acuerdo se ha cumplido parcialmente, es decir, tiene una existencia institucional porque está en el papel, también tiene una existencia imaginada porque así se reconoce en la ciudad, se evoca como pueblo y es representativo por su historia, pero no existe en la realidad, porque no se han mantenido los aspectos arquitectónicos necesarios para su pervivencia.

Tumbaron muchas casas y hay mucho comercio. Antes era muy sano, ahora tienen problemas con la plaza, porque van a hacer una troncal, porque Ibagué debe crecer hacia abajo. Han arreglado las calles, pero ya se dañaron, no ha logrado ser un pueblito tolimense (Habitante de 54 años, 40 años en el barrio; Entrevista XXIV, 2019).

Para Silva (2013), los imaginarios urbanos son tipos de acercamientos que sostienen el modelo de ciudad imaginada, en este caso lo imaginado es dominante y se encarna en un objetivo o espacio físico de la ciudad que lo mantiene, es este caso el barrio como Pueblito Tolimense 3 . Los lugares albergan la historia y otra forma de apropiarlos también es desde el recuerdo de lo que son ahora y lo que fueron antes. Porque esta

\footnotetext{
${ }^{3}$ Silva (2013) propone este modelo tríadico de encarnación de los imaginarios urbanos como tipos de acercamientos de producción social de imaginarios urbanos que sostienen el modelo de ciudad imaginada. Realidad 1: R=I Imaginada - real: Lo imaginado es dominante y lo real lo potencia. Realidad 2: R=R Real - imaginada: Lo real es dominante y lo imaginado lo potencia. Realidad 3: I=R=I Imaginada - real - imaginada: Lo imaginado es equivalente a lo real y en la dinámica de los imaginarios se reconstituye como imaginario.
} 
historia está incorporada simbólicamente en las construcciones (Rodríguez Becerril, 2016; Delgadillo Polanco, 2016).

Las ferias, las corralejas... era que El Salado era un barrio más turístico de lo que es ahora, es que era un pueblo, alejado del centro de Ibagué. Lo que estamos viendo de transformaciones ahora son las torres de apartamentos no existían, eran casas de bahareque, era un pueblo como vuelvo y le digo... Esto [las construcciones] acaba la dinámica del barrio porque deja de ser turístico y se vuelve un barrio común, de la comuna (Habitante de 52 años, 40 años en el barrio; Entrevista III, 2019).

Tenían el proyecto del pueblito tolimense, pero no se ha dado, pero ya no se puede, hay construcciones por todo lado, las casas antiguas ya desaparecieron, la construcción aísla demasiado, la gente llega de trabajar y ya no sabe quién es el vecino, esto daña las relaciones, no saben dónde viven sus vecinos, cambia la interacción y la comunicación (Habitante de 61 años, 5 años en el barrio; Entrevista XXII, 2019).

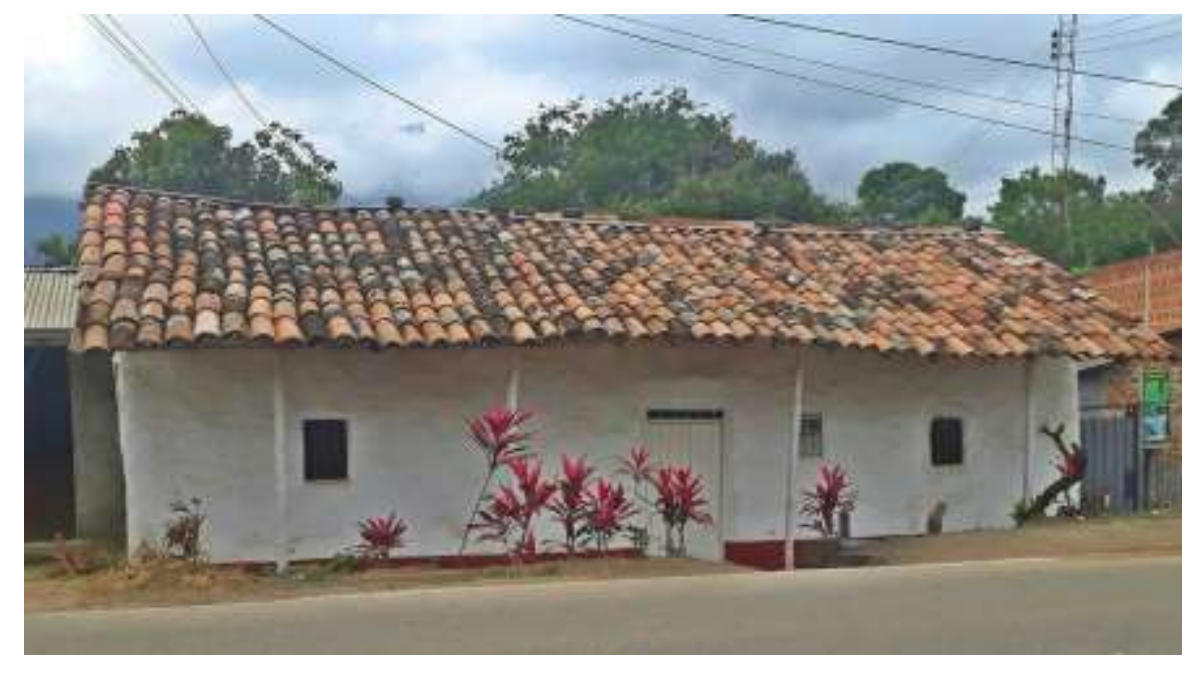

Figura 7 - Casa en bahareque del barrio Especial El Salado. Fuente: Angie Rubiano (2016).

Estas casas de la figura 7 remiten al imaginario colectivo rural que pesa sobre El Salado, pero también, aunque el pueblito tolimense no existe en la realidad, sí se mantiene vivo en las percepciones de los habitantes de la ciudad, que caracterizaron a El Salado como pueblo.

\section{Entre barrio, pueblo y pueblito tolimense}

La principal alusión al barrio, por parte de los habitantes de Ibagué, fue la categoría pueblo (33\%). Debemos entender la palabra pueblo en contraposición a la de ciudad, el pueblo es lo que no hace parte de la ciudad, tiene características rurales y sus habitantes se comportan diferente a los citadinos. De allí la concepción del barrio El Salado como otredad de la ciudad de Ibagué. De esta manera, aparece el barrio El Salado como otredad de la ciudad en general. No obstante, estos imaginarios no permiten ahondar en procesos más puntuales de representatividad del barrio, es decir, "los procesos de subjetivación de los imaginarios en los que se alude a los estilos de vida de los ciudadanos a partir de cierta imaginería sobre lo urbano" (Vera et al., 2019, p. 23).

Un aspecto central que se evidenció sobre esos procesos de subjetivación en El Salado es su carácter de barrio inserto en lo urbano y en lo rural, es decir, un territorio que se configura en una dinámica constante urbano-rural. Podemos afirmar que históricamente lo que ha sucedido en el barrio El Salado es un proceso de urbanización de lo rural "el proceso actual de expansión urbana viene originando cambios sociales al interior del espacio y sus pobladores que, desde el campo, se han visto sumidos a transformaciones de sus medios de vida, paradójicamente sin haber emigrado" (Pérez-Martínez, 2016, p. 105). Sin embargo, y para El Salado, también se mantiene vigente un proceso de ruralización de lo urbano, como si lo rural nunca hubiera desaparecido del territorio y de las formas de configuración de significados por parte de los habitantes.

Cimadevilla y Kenbel $(2009$, p. 6) afirman que "se hacen visibles en el seno de una urbe [...] algunos actores cuyas lógicas de acción comprenden saberes, valores, prácticas y dispositivos asociados a lo rural”. 
En esa medida, El Salado es un territorio urbano-rural cuya apropiación simbólica está relacionada precisamente con una concepción imaginada del espacio urbano y rural en el que están ubicados, una historia rural y una proyección de futuro como destino agroturístico.

El pueblito tolimense [...] está en el imaginario colectivo, la gente sabe que El Salado lo es, se ha fortalecido por el turismo. Viene un fin de semana y es urbano-rural, llega el campesino con la carabana de mulas con la carga de café. Eso solo se ve en El Salado. Se mantienen vivas sus tradiciones. Aquí nació el festival a través de las verbenas o fiestas de pueblo (Habitante de 77 años, 4 años en el barrio; Entrevista XXI, 2019).

La apropiación del territorio se da en la medida que este adquiere aspectos simbólicos y significados compartidos, que crean identidad, pertenencia y satisfacción por permanecer en el lugar (Boisier, 2011; Reyes-Guarnizo, 2014). Las versiones de la historia del barrio están ancladas a un deseo colectivo de vivir en El Salado como se vive en un pueblo, de ser un Pueblito Tolimense. Sin embargo, todo lo anterior entraña una contradicción. La contradicción aquí tiene ver con el imaginario de El Salado como pueblo, su evocación como Pueblito Tolimense en el que lo histórico y patrimonial son muy importantes pero que, en la realidad del crecimiento de la ciudad, se encuentran con el desarrollo urbanístico que hace que las casas desaparezcan y se construyan edificios. Se trata de dos imaginarios diferentes de temporalidades: uno posmoderno y otro patrimonialista en la que se confrontan el presente con el legado del pasado (Hiernaux, 2006).

Lo que encontramos ahora en el barrio es que por encima de la torre de la iglesia están las torres de apartamentos en construcción, es decir, un espacio que se moldea de acuerdo con las necesidades de expansión, pero que deja de lado las formas en las que históricamente se ha configurado el territorio y las apropiaciones de los habitantes.

Pero ahora hay muchas construcciones y muchas personas nuevas, ha crecido bastante. Antes era un pueblo y ahora es muy turístico y quieren hacerle arreglos a la plaza de mercado por el tema de las basuras, viene mucha gente y se lo podría dar una mejor cara. Pero hay gente que vive hace mucho tiempo en el barrio y no quiere que cambie, quieren mantener las tradiciones y la historia (Habitante de 36 años, 10 años en el barrio; Entrevista V, 2019).

Compartimos con Monnet (2015) que el espacio público se crea en el uso social y estos usos están ligados a las temporalidades de los ciudadanos. Sobre esto mismo Silva (2004) afirma que las temporalidades son marcas temporales que realizan los ciudadanos en el espacio, es decir, croquis de tiempo que caracterizan sus rutinas y median sus acciones. De acuerdo con el proceso de observación del barrio y las entrevistas realizadas, podemos afirmar que en el barrio El Salado hay temporalidades muy marcadas en el uso social del espacio público. En este caso, el espacio principal del barrio es el parque central. Las rutinas cotidianas de los ciudadanos y el clima cálido de la ciudad afectan los usos del espacio, por ejemplo, las actividades deportivas inician hacia las 5:00 p.m. y terminan en la noche. Los niños van al parque en la tarde porque en la mañana tienen jornada escolar y las mujeres hacen ejercicio muy temprano antes de salir a trabajar o dedicarse a las labores de su casa.

En la lectura tríadica propuesta por Silva $(2004)^{4}$, las temporalidades de los ciudadanos (primeridad) dejan marcas en el espacio (segundidad), en este caso, en el parque del barrio y se generan representaciones generalizadas (terceridad) (Restrepo, 2007).

Ahora bien, ciertas apropiaciones son vistas como conflictivas. Una tiene que ver con la calidad de espacio público y la otra con las apropiaciones abusivas (Monnet, 2015). En el primer caso tenemos las referencias constantes al estado del parque. Algunas personas hacen referencia a la ausencia de columpios o de los elementos necesarios de un parque infantil, por eso tienen que pagar para que los niños jueguen en otros

\footnotetext{
${ }^{4}$ En el modelo tríadico de Peirce, el autor plantea "una visión integrada de la existencia a partir de unos "pocos conceptos simples" que él denominó "categorías universales" [...] Esta concepción tríadica del ser como estructura abierta y continua le permite a Peirce explicar la realidad, el conocimiento y el hombre. La realidad existe externa al hombre pero es mera posibilidad, hasta cuando se accede a ella como representación en una mente humana, es decir, en el pensamiento, que es mediación necesaria de todo conocimiento" (Restrepo, 2007, p. 104-105). Silva retoma este modelo y lo aplica en su teoría de los imaginarios urbanos.
} 
elementos como saltarines, que traen los fines de semana. A través del proceso de observación se logró identificar que el parque infantil está roto y oxidado.

El parque principal es la cara del Salado, todo el mundo viene acá y como usted ve está insoportable este parque, entonces pueda ser que la transformación del parque sea pronto, dijeron que este mes empezaban, pero todavía no se ha visto nada (Pensionada, toda la vida en el barrio; Entrevista I, 2019).

El segundo caso se refiere a las apropiaciones que se dan a altas horas de la madrugada por parte de consumidores de sustancias alucinógenas y los conflictos que se generan a raíz del alcohol, específicamente las riñas que, según señalan los entrevistados, son una constante en el barrio. Si el parque es el referente central de espacio público en el barrio El Salado es porque sobre éste pesan calificaciones y cualidades que lo convierten en un símbolo (Monnet, 2015).

Recordemos también que Silva (2004) señala que las calificaciones que hacen los ciudadanos sobre su ciudad tienen que ver con sus formas de marcarla y de ella derivan perfiles específicos, es decir, información sobre las necesidades de la ciudad o los aspectos a resaltar. Para el caso de la encuesta de Ibagué imaginada, el parque El Salado fue calificado negativamente, en la escala de uno a cinco, el $77 \%$ de las personas encuestadas escogió las escalas 1, 2 y 3; mientras que un 18 \% escogió 4 y 5 (Lopera et al., 2019). Las anteriores calificaciones contrastan con las respuestas de los entrevistados del barrio porque, a pesar de que reconocen que el parque está deteriorado, sigue siendo un lugar representativo.

Los lugares, en este caso el parque de El Salado, "son producto de actores que los usan, significan y simbolizan en un despliegue constante de prácticas, de memoria y de proyección imaginal" (Vergara, 2006, p. 151). A pesar de no tener las condiciones óptimas para el disfrute ciudadanos, en el parque se practican diferentes deportes, principalmente, baloncesto y fútbol, y los niños juegan en el parque infantil.

Vergara (2006, p. 153) también señala que "el parque funciona como un otro de la ciudad en el que se socializa con los demás, posibilita los encuentros, la convivencia, el valor de acceso y la expresividad estética". Por esta razón, es el lugar predilecto para la tertulia con los amigos.

El croquis afectivo del barrio El Salado se extiende más allá de sus límites político-administrativos y, más que un barrio dentro de una comuna, el barrio se percibe como la comuna en su totalidad, como se muestra en la figura 8. No obstante, los significados del territorio se concentran en dos lugares históricos que son la plaza y el parque del barrio, en los que pudimos identificar que se concentran los usos cotidianos de los habitantes. Además, el croquis se hace urbano-rural por las conexiones históricas y culturales con el campo; las fiestas tradicionales; y las fincas de descanso y para prácticas agroturísticas.

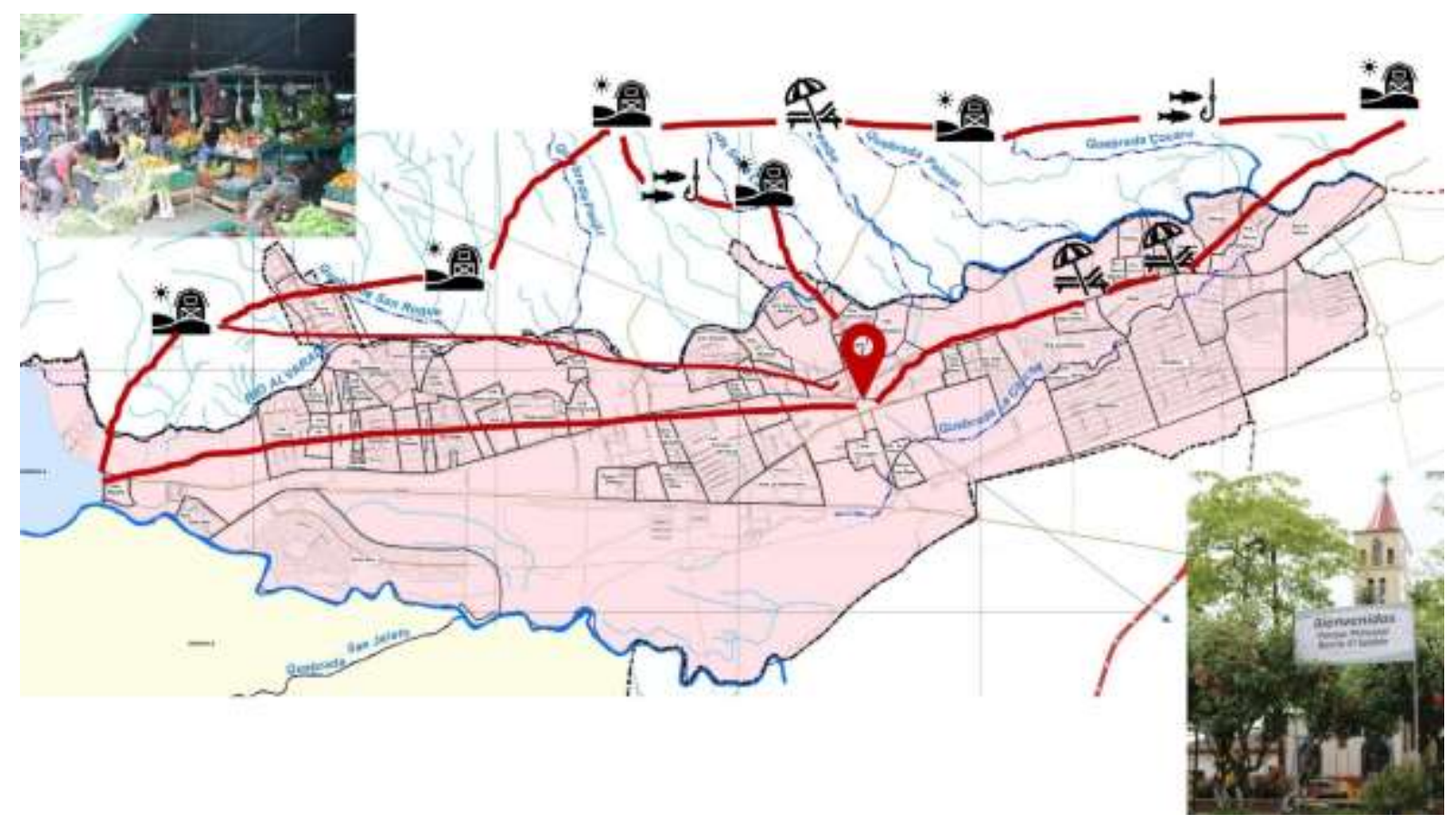

Figura 8 - Croquis afectivo de El Salado. Fuente: Los autores (2019). 


\section{Reflexiones finales: proyecciones en la configuración del espacio}

Los resultados expuestos previamente nos permitieron responder a las dos preguntas de investigación, la primera, sobre los imaginarios urbano-rurales que surgen de las percepciones de los habitantes de El Salado sobre su propio barrio y, la segunda, las formas de significación que adquiere el territorio para los habitantes del barrio El Salado de la ciudad de Ibagué.

Los imaginarios urbanos nos hablaron de El Salado como un lugar periférico, lejano, turístico, de diversión, caliente y con características rurales. Se asoció con sentimientos de miedo por sus imaginarios de mal olor y con desagrado por la suciedad. Estas evocaciones se contrastaron con los imaginarios de los mismos habitantes de El Salado, quienes convierten el territorio en un hecho vivencial, por lo tanto, con mayor carga simbólica. El territorio, al materializar la cultura, se convierte es un espacio de significaciones que es defendido por los habitantes, quienes destacan el valor histórico que los acerca más a las tradiciones rurales; por eso la consideración teórica de comprender el territorio como un espacio urbano-rural.

La caracterización de los usos de ciertos lugares del barrio, principalmente el parque y la plaza, remite a las formas de vida de los habitantes. El parque porque es el espacio público principal, es decir, por metonimia es El Salado en sí. Las temporalidades de los ciudadanos se hacen rutinas al marcar el espacio con sus acciones. Allí está presente lo cultural, deportivo, religioso y el ocio en general. Por su parte, la plaza de mercado combina las temporalidades de los habitantes que acceden al lugar a hacer las compras, las temporalidades de los turistas que llegan los fines de semana y en periodo de vacaciones a buscar platos típicos y, finalmente, las temporalidades de los campesinos que llegan los domingos a vender sus productos. Este diálogo con los campesinos es también culturalmente significativo en la dinámica del territorio urbano-rural.

En el barrio El Salado también sucede la doble codificación del espacio urbano que surge de la articulación o no articulación entre las formas de concebir el territorio por parte de los urbanistas y las formas en las que los ciudadanos se apropian del espacio. La institucionalidad construyó una nueva plaza de mercado que aún no ha sido apropiada por los trabajadores de la antigua plaza, porque no la siente propia.

Cuando estuve en la Junta, hace 40 años, hicimos esta antigua plaza, esto no es de la Alcaldía, esto es de nosotros. (Habitante de 82 años, toda la vida en el barrio; Entrevista XIV, 2019).

Algunos habitantes hablan de un progreso o de un desarrollo que es necesario para el barrio, pero otros temen la pérdida definitiva de lo que caracteriza al barrio como pueblo y lo que algún día podría convertirlo en Pueblito Tolimense. Esta es precisamente la contradicción entre los imaginarios temporales del pasado, del presente y del futuro. Hiernaux (2006) afirma que lo que se modifica en esta articulación de lo histórico con lo moderno son los modos de vida de los habitantes. Lo que está en juego en estas proyecciones imaginadas del barrio es su configuración misma, es decir, lo urbano-modernizador en diálogo o enfrentamiento con lo urbano-rural.

Ahora bien, más allá del uso del espacio público está la capacidad que tienen para lograr la integración, la interacción y la cohesión social. Estos espacios son la evidencia de quienes los habitan, de sus creencias y valores. "Los profesionales del urbanismo y los gobiernos locales deberían aprovechar los conocimientos que da la experiencia de vivir cotidianamente en un lugar concreto" (Ortiz Guitart, 2006, p. 81) para incorporar en sus diseños, los imaginarios urbanos, pero sobre todo las necesidades y las proyecciones que tienen de su vida en el lugar.

Lo anterior implica lograr un diálogo entre quienes aprueban más construcciones y también aprueban un Acuerdo que institucionaliza al Salado como Pueblito Tolimense con los habitantes del barrio, con quienes viven el territorio, lo marcan y configuran con sus acciones diarias la ciudad deseada, en este caso, el barrio deseado. Esto significa, potenciar lo que está en el imaginario para convertirlo en emblema de una ciudad y no que la otredad deslegitime su derecho a la ciudad (Palacios-Gámaz, 2010). De allí que la relación de otredad entre el centro y la periferia podría reconfigurarse en torno a otros deseos ciudadanos alrededor de nuevas prácticas cotidianas.

Los imaginarios que subyacen a los modos de apropiación del espacio de este caso en concreto nos permiten reflexionar más allá del barrio en sí y plantear la discusión sobre la necesidad de los estudios urbanos. Esto significa que los estudios sobre el territorio no pueden quedar relegados a un segundo plano y mucho menos el papel que cumple el ciudadano en la construcción social de este (Boisier, 2011). En suma, la ciudad es alterada por su producción simbólica, lo que está en juego en estas proyecciones imaginadas 
del barrio es su configuración misma, es decir, lo urbano-modernizador en diálogo con lo urbano-rural que deja de ser una categoría de oposición, sino más bien de conjunción para ser analizada en otros territorios.

\section{Referencias}

Acosta, J. Entrevista VI. (15 de junio de 2019). Carlos Mauricio Santana Sáenz. Ibagué, 2019.

Alcaldía Municipal de Ibagué (2016). Plan de Desarrollo Municipal 2016-2019. “Ibagué con todo el corazón”. Ibagué: Alcaldía de Ibagué.

Aliaga, F, Maric, M. L., \& Uribe, C. J. (Eds.). (2018). Imaginarios y representaciones sociales: Estado de la investigación en Iberoamérica (1 ed.). Bogotá: Universidad Santo Tomás.

Antequera, N. (2007). Territorios urbanos. Cochabamaba, Bolivia: Centro de Documentación e Información Bolivia, CEDIB.

Arizaga, M. C. (2000). Murallas y barrios cerrados. La morfología espacial del ajuste en Buenos Aires. Nueva Sociedad, (166), 22-32.

Ávila Sánchez, H. (Coord.). (2005). Lo urbano-rural, ¿nuevas expresiones territoriales? (1 ed.). Cuernavaca: Universidad Nacional Autónoma de México.

Boisier, S. (2011). El territorio en la contemporaneidad (La recuperación de las políticas territoriales). Revista Líder, 18 (13), $9-24$.

Carrión, F. (2016). El espacio público es una relación, no un espacio. En Ramírez-Kuri, P. (Coord.), La reinvención del espacio público en la ciudad fragmentada (1 ed., p. 13-50). México: Universidad Nacional Autónoma de México.

Centro de Información Municipal para la Planeación Participativa (CIMPP), (s.f.). Cartografía Urbana. Comuna 7. Recuperado el 6 de junio de 2019, de: https://cimpp.ibague.gov.co/cartografia-urbana/

Ciccolella, P. (2011). Metrópolis latinoamericanas: más allá de la globalización. Quito: Crearimagen.

Cimadevilla, G., \& Kenbel, C. (2009). La rurbanidad desde el enfoque de las memorias sociales. En X Jornadas Argentinas de Estudios de Población (p. 1-25). San Fernando del Valle de Catamarca: Asociación de Estudios de Población de la Argentina.

Correal, A. Entrevista V. (19 de mayo de 2019). Carlos Mauricio Santana Sáenz. Ibagué, 2019.

Delgadillo-Polanco, V. (2016). Ciudad de México, disputas por el patrimonio urbano y el espacio público. En Ramírez-Kuri, P. (Coord.), La reinvención del espacio público en la ciudad fragmentada (1 ed., p.135-170). México: Universidad Nacional Autónoma de México.

Delgado, M. (2007). Ciudadano, mitodano. En Silva, A. (Eds). Imaginarios urbanos en América Latina: urbanismos ciudadanos (p.179-187). Barcelona: Fundación Antoni Tápies.

García Ayala, J. A. (2016). Espacios de uso público y resolución de conflictos en la Jardín Balbuena. En Ramírez-Kuri, P. (Coord.), La reinvención del espacio público en la ciudad fragmentada (1 ed., p. 269-302). México: Universidad Nacional Autónoma de México.

García-Canclini, N. (2010). Imaginarios urbanos. Buenos Aires: Eudeba.

Giménez, G. (2005). Breve introducción a la geografía cultural. Trayectorias, 7(17), 8-24.

Gómez, A. Entrevista XXII. (2 de abril de 2019). Carlos Mauricio Santana Sáenz. Ibagué, 2019.

Gordillo, M. Entrevista XXI. (15 de junio de 2019). Carlos Mauricio Santana Sáenz. Ibagué, 2019

Guerrero Valdebenito, R. M. (2006). Nosotros y los Otros: Segregación urbana y significados de la inseguridad en Santiago de Chile. En Lindón, A., Hiernaux, D., \& Aguilar, M.A. (Coord.), Lugares e imaginarios en la metrópolis (p.107-118). España: Anthropos.

Hiernaux, D. (2006). Los centros históricos: ¿espacios posmodernos? (De choques de imaginarios y otros conflictos). En Lindón, A., Hiernaux, D., \& Aguilar, M.A. (Coord.), Lugares e imaginarios en la metrópolis (p. 27-42). España: Anthropos.

Hussein, A. (2009). The use of Triangulation in Social Sciences Research: Can qualitative and quantitative methods be combined. Journal of Comparative Social Work, 4 (1), 1-12. doi 10.31265/jcsw.v4i1.48

Ibagué (1988). Acuerdo Municipal no. 74, de 1988. Por el cual se institucionaliza El Salado como patrimonio turístico de la ciudad musical de Colombia. Ibagué: Concejo municipal de Ibagué. 
Ibagué (2009, 11 de mayo). Acuerdo Municipal no. 009, del 11 de mayo de 2009. Por el cual se institucionaliza como pueblito tolimense dentro del barrio especial El Salado y se dictan otras disposiciones. Ibagué: Concejo municipal de Ibagué.

Ibagué (2012, noviembre). Plan estratégico de desarrollo de la comuna 7 de Ibagué de 2012. Ibagué: Consejo comunal de planeación, Asojuntas comuna 7.

Ibagué (2016-2017). Anuario estadístico municipal 2016-2017. Ibagué: Secretaría de Planeación Municipal.

Jaramillo Paredes, D. (2013). La ciudad imaginada Los territorios, lo imaginario y lo simbólico. Estoa, (2), 27-37.

Lindón, A. (2006). Del suburbio como paraíso a la espacialidad periférica del miedo. En Lindón, A., Hiernaux, D., \& Aguilar, M. A. (Coord.), Lugares e imaginarios en la metrópolis (p. 85-106). España: Anthropos.

Lindón, A., Hiernaux, D., \& Aguilar, M.A. (Coord.), (2006). Lugares e imaginarios en la metrópolis. España: Anthropos.

Lopera, A. M., Santana, C. M., Molano, N., Hernández, T. \& Martínez, Y. (2019). Ibagué imaginada. Ibagué: Ediciones Unibagué.

Ochoa, J. Entrevista III. (2 de mayo de 2019). Carlos Mauricio Santana Sáenz. Ibagué, 2019.

Ortiz Guitart, A. (2006). Usos de los espacios públicos y construcción del sentido de pertenencia de sus habitantes en Barcelona. En Lindón, Hiernaux \& Aguilar (Coord.), Lugares e imaginarios en la metrópolis (p. 67-84). España: Anthropos.

Martel, R. \& Baires, S. (2006). Imaginarios del miedo y geografías de la inseguridad: construcción social y simbólica del espacio público en San Salvador. En Lindón, Hiernaux \& Aguilar (Coord.), Lugares e imaginarios en la metrópolis (p.119-136). España: Anthropos.

Martínez-Valle, L. (2012). Apuntes para pensar el territorio desde una dimensión social. Ciencias Sociais Unisinos, 48(1), 12-18.

Mazurek, H. (2005). Redefinir el Territorio para definir una constitución. En I Encuentro Internacional sobre Territorialidad y Política: "Territorialidades, Autonomías y Ciudadanías" (p. 1-20). Bolivia: GTZ - DFID - Ministerio de Participación Popular.

Méndez, M. (2005). Contradicción, complementariedad e hibridación en las relaciones entre lo rural y lo urbano. En Sánchez, H. Á. (Coord.), Lo urbano-rural, ¿nuevas expresiones territoriales? (p. 87-122). Cuernavaca: Universidad Nacional Autónoma de México.

Monnet, J. (2015). El espacio público definido por sus usos: una propuesta teórica. En VIII Seminario internacional sobre territorio y cultura: Perspectivas actuales de la investigación sobre el territorio (p. 1-15). España: Universidad Nacional de Educación a Distancia, Colombia: Universidad de Caldas (Colombia).

Palacios-Gámaz, A. (2010). Representaciones sociales de la otredad y la ciudad. Revista Austral de Ciencias Sociales, $18,35-58$.

Pecqueur, B. (2009). De l'exténuation à la sublimation: la notion de territoire est-elle encore utile ? Geographie Economie Societe, 11(1), 55-52.

Pérez-Martínez, M. E. (2016). Las territorialidades urbano rurales contemporáneas. Bitácora, 26(2), 103-112.

Pérez-Rincón, S., Vives, A., García, A., \& Expósito, C. (2012). Reproducción de la otredad inmigrante en Barcelona y recepción popular del espacio urbano representado como "gueto". Revista de Ciencias Sociales, (29), 160-182.

Petzol-Rodríguez, A. (2016). Modos de ver y pensar lo público en Maracaibo, Venezuela. En Ramírez-Kuri, P. (Coord.), La reinvención del espacio público en la ciudad fragmentada (p.565-597). México: Universidad Nacional Autónoma de México.

Portal, M. A. (2016). El espacio público: ¿de quién y para quiénes? En Ramírez-Kuri, P. (Coord.), La reinvención del espacio público en la ciudad fragmentada (p. 365-388). México: Universidad Nacional Autónoma de México.

Ramírez, B. Entrevista XIV. (25 de junio de 2019). Carlos Mauricio Santana Sáenz. Ibagué, 2019.

Restrepo, M. (2007). Lógica e imaginarios tan simple como uno, dos y tres. En Silva, A. Imaginarios urbanos en América Latina: urbanismos ciudadanos (p. 104-106). Barcelona: Fundación Antoni Tápies.

Reyes-Guarnizo, A. (2014). De los imaginarios colectivos a la apropiación del territorio: Un recorrido conceptual. Bitácora Urbano Territorial, 24(11), 11-18.

Rico, M. Entrevista XXIV. (15 de junio de 2019). Carlos Mauricio Santana Sáenz. Ibagué, 2019.

Rodríguez Becerril, V. (2016). El Zócalo de la ciudad de México. La disputa por la plaza pública desde su uso cultural. En Ramírez-Kuri, P. (Coord.), La reinvención del espacio público en la ciudad fragmentada (p. 171-208). México: Universidad Nacional Autónoma de México.

Saavedra, L. M. Entrevista I (8 de abril de 2019). Carlos Mauricio Santana Sáenz. Ibagué, 2019. 
Salvatierra, K. S. (2016). Presencias efímeras: mujeres de "la Guerrero". Género y relaciones de poder en el espacio público urbano de la ciudad de México. En Ramírez-Kuri, P. (Coord.), La reinvención del espacio público en la ciudad fragmentada (p.439-470). México: Universidad Nacional Autónoma de México.

Santillán, A. (2019). Imaginar fronteras, reconstruir desigualdades. En Vera, P., Gravano, A., \& Aliaga, F. (Eds.), Ciudades (in)descifrables: imaginarios y representaciones sociales de lo urbano (p. 107-120). Bogotá: Editorial Unicen.

Silva, A. (2004). Imaginarios urbanos: hacia el desarrollo de un urbanismo desde los ciudadanos. Metodología. Bogotá: Convenio Andrés Bello, IECO de la Universidad Nacional.

Silva, A. (2006). Imaginarios urbanos (5 ed.). Bogotá: Arango Editores.

Silva, A. (2007). Imaginarios urbanos en América Latina: urbanismos ciudadanos. Barcelona: Fundación Antoni Tápies.

Silva, A. (2011). Ciudades imaginadas. En Bedoya, O. L., Pereira imaginada (p. 19-37). Pereira: Universidad Tecnológica de Pereira.

Silva, A. (2013). Imaginarios, el asombro social. Bogotá: Universidad Externado de Colombia.

Silva, A. (2015). Hacia la Ibagué imaginada. En Cátedra Fundadores 2015 (p. 227-236). Ibagué: Universidad de Ibagué.

Silva, A. (2019). Imaginarios urbano-barriales de una ciudad media. En Vera, P., Gravano, A., \& Aliaga, F. (Eds.), Ciudades (in)descifrables: imaginarios y representaciones sociales de lo urbano (p. 121-140). Bogotá: Editorial Unicen.

Vera, P. (2018). Imaginarios del patrimonio en los procesos de reconversión urbana. Puerto Norte, Rosario, Argentina. URBE. Revista Brasileira de Gestão Urbana, 10(1), 49-67.

Vera, P., Gravano, A., \& Aliaga, F. (Eds.). (2019). Ciudades (in)descifrables: imaginarios y representaciones sociales de lo urbano. Bogotá: Editorial Unicen.

Vergara, A. (2006). Espacio, lugar y ciudad: etnografía de un parque. En Lindón, A., Hiernaux, D., \& Aguilar, M.A. (Coord.), Lugares e imaginarios en la metrópolis (p.137-148). España: Anthropos.

Winocur, R. (2009). Robinson Crusoe ya tiene celular. México: Siglo veintiuno editores.

Editor responsável: Rodrigo Firmino

Recibido en 01 abr. 2020

Aprobado en 06 sep. 2020 